\title{
The epidemiology of irritable bowel syndrome
}

This article was published in the following Dove Press journal:

Clinical Epidemiology

4 February 2014

Number of times this article has been viewed

\section{Caroline Canavan \\ Joe West \\ Timothy Card \\ Division of Epidemiology and Public Health, University of Nottingham, Nottingham, UK}

Correspondence: Caroline Canavan Division of Epidemiology and Public Health, University of Nottingham, Clinical Sciences building, City Hospital Campus, Hucknall Road, Nottingham, UK Email Caroline.Canavan@nottingham. ac.uk

\begin{abstract}
Irritable bowel syndrome (IBS) is a functional condition of the bowel that is diagnosed using clinical criteria. This paper discusses the nature of the diagnostic process for IBS and how this impacts epidemiological measurements. Depending on the diagnostic criteria employed, IBS affects around $11 \%$ of the population globally. Around $30 \%$ of people who experience the symptoms of IBS will consult physicians for their IBS symptoms. These people do not have significantly different abdominal symptoms to those who do not consult, but they do have greater levels of anxiety and lower quality of life. Internationally, there is a female predominance in the prevalence of IBS. There is $25 \%$ less IBS diagnosed in those over 50 years and there is no association with socioeconomic status. IBS aggregates within families and the genetic and sociological factors potentially underlying this are reviewed. Patients diagnosed with IBS are highly likely to have other functional disease and have more surgery than the general population. There is no evidence that IBS is associated with an increased mortality risk. The epidemiological evidence surrounding these aspects of the natural history is discussed.
\end{abstract}

Keywords: irritable bowel syndrome, epidemiology, prevalence, mortality, natural history

\section{Introduction}

The epidemiology of any condition is an expansive topic, covering many subjects that individually could warrant devoted review articles. Irritable bowel syndrome (IBS) is no different. The intention of this review is to provide a brief overview of the fundamental issues of epidemiological interest relating to IBS. We discuss the diagnostic process and variation in how IBS is defined, how many of the population have IBS based upon these definitions, which members of the population are most likely to be affected, and discuss key aspects of the natural history, including symptom fluctuation and the association with other functional conditions.

In compiling this review, potentially relevant articles were identified through a literature search using MEDLINE and Embase of English language papers published since the first formal definition of IBS in 1978 until August 1, 2013. Medical subject headings (MeSH) used were 'irritable bowel syndrome' or 'IBS' or 'irritable colon' or 'functional bowel disease' combined with 'epidemiology' or 'incidence' or 'prevalence' or 'natural history' or 'mortality'. The references of these papers were reviewed for additional important papers not initially captured.

\section{What is IBS?}

IBS is a chronic functional disorder of the gastrointestinal system. Patients experience abdominal pain and altered bowel habit, with either predominantly diarrhea (IBS-D), 
constipation (IBS-C), or both (IBS-M). There is no definitive investigation as no biomarker has been found, so IBS is diagnosed clinically. The earliest reports describing IBS are from the turn of the 19th and 20th century. ${ }^{1}$ At this time, diagnosis was only made by exclusion of malignant, inflammatory, or infectious disease after full investigation and "extensive unsuccessful surgeries." IBS remained "frequently misdiagnosed and poorly understood"3 into the 1970s, with the problem of unsuccessful, or unnecessary, surgery continuing. ${ }^{3}$

In an attempt to standardize and define IBS and reduce unnecessary surgery, Manning created the first set of formal criteria that allowed IBS to be positively diagnosed without the need for extensive investigations to exclude other diagnoses. These criteria were developed through expert consensus to create the Rome criteria, now in their third iteration. ${ }^{4}$ The Rome criteria also recommend that IBS should be a positive diagnosis but are more restrictive than the Manning criteria. When assessing the epidemiology of IBS, the diagnostic criteria employed are important to consider as they reflect how cases are ascertained and the differences between studies and over time. Most studies use either the Manning, Rome II, or Rome III criteria, and the variation between these can be seen in Table 1. It is argued that the Rome criteria are only useful for clinical trials and not for clinical practice. The criteria have been compiled by secondary and tertiary care specialists who undoubtedly see a different population of patients than are seen in primary care where the criteria are recommended to be implemented. Clinicians frequently use other clinical findings (such as bloating and psychological stress) to assist in diagnosing IBS and do not adhere to the criteria. ${ }^{5,6}$ Some even suggest that attempts to sub-type functional gastrointestinal disease are arbitrary and IBS should remain a diagnosis of exclusion..$^{6-8}$ International best practice guidelines disagree with this stance and promote positive diagnosis using the Rome criteria. ${ }^{9}$
The validity of these diagnostic criteria has been studied; however, this has not been done using conventional measurement of sensitivity and specificity in general population samples because there is no gold standard to allow independent confirmation of diagnosis, such as a biomarker. Instead estimations of specificity have been made among those with organic gastrointestinal disease, and sensitivity amongst cases who have already presented and been diagnosed (potentially an atypical minority). All of these criteria have modest specificity to diagnose IBS in those with organic gastrointestinal disease of about $0.7 .{ }^{10}$ This reflects the fact that the symptoms experienced in IBS are common to other gastrointestinal conditions. Specificity is increased to 0.9 if patients with red flag symptoms such as anemia, weight loss, and rectal bleeding (present in just 3\% of patients) ${ }^{11}$ are more extensively investigated and IBS is diagnosed by exclusion. ${ }^{10}$ Sensitivity across the criteria ranges from 0.4 to 0.9 depending on the experience of the clinician, ${ }^{10}$ possibly reflecting variation in confidence to use criteria for positive diagnosis.

\section{How much IBS is there?}

As outlined above, there is no gold standard case definition of IBS. Diagnostic criteria have not been standardized over time and they have a large margin of error in their application. ${ }^{5,8,15}$ The definition of cases in epidemiological studies is therefore difficult and there may be limited opportunities for ascertainment of cases. There is no specific or standardized therapy, with many of the preparations available over the counter and some patients not requiring any medication, ${ }^{15,16}$ so prescription data have limited use. Few patients will be admitted to hospital with IBS or diagnosed during an admission, ${ }^{17}$ and IBS is not considered a cause of death so these data are also not useful to define cases. The methods chosen to define and ascertain cases will clearly affect the number of cases found.

Table I Comparison of the Manning and Rome diagnostic criteria frequently used in epidemiological studies for case ascertainment

\begin{tabular}{|c|c|c|c|}
\hline Manning (1978) ${ }^{12}$ & Rome I (1 989) ${ }^{13}$ & Rome II (I 999) ${ }^{14}$ & Rome III (2006) \\
\hline 2 or more of the following & At least 3 months of continuous & At least 12 weeks in past 12 months & At least 3 days per month in \\
\hline symptoms: & or recurrent abdominal pain: & of continuous or recurrent abdominal & past 12 weeks of continuous \\
\hline Abdominal distension & Relieved with defecation & pain or discomfort & or recurrent abdominal pain \\
\hline Pain relief with defecation & or & With at least 2 of the following: & or discomfort \\
\hline Frequent stools with pain & Associated with change in stool consistency & Relief with defecation & With at least 2 of the \\
\hline Looser stools with pain & With at least 2 of the following on at least & Altered stool frequency & following: \\
\hline Passage of mucus & $25 \%$ of days: & Altered stool form & Relief with defecation \\
\hline Sensation of incomplete & Altered stool frequency & Onset of symptoms more than & Altered stool frequency \\
\hline \multirow[t]{4}{*}{ evacuation } & Altered stool form & I 2 months before diagnosis & Altered stool form \\
\hline & Altered stool passage & & Onset of symptoms more \\
\hline & Passage of mucus & & than 6 months before \\
\hline & Bloating or abdominal distension & & diagnosis \\
\hline
\end{tabular}




\section{Incidence}

Symptoms associated with IBS are commonly experienced within the population, it has an insidious onset, and frequently does not result in medical care. ${ }^{16,18}$ Consequently, there is discrepancy between incidence of the first occurrence of symptoms, which occur within the community, and the first diagnosis of IBS, which will occur after visiting a physician. ${ }^{16}$ Consequently, few studies calculate the incidence of IBS.

One study in the USA using first occurrence of IBS symptoms within the community estimated the incidence of new IBS by conducting two population cohort surveys 1 year apart. Of patients with no IBS symptoms and no diagnosis of IBS in the baseline survey, $9 \%$ had developed symptoms over the year, an incidence rate of 67 per 1,000 person-years. ${ }^{19}$ Studies that opt for defining cases as first diagnosis by a physician produce more conservative estimates of around two per 1,000 person years..$^{20-22}$

\section{Global prevalence}

Prevalence estimates for IBS vary greatly internationally, both within and between countries, as shown in Figure 1 and Table 2.

Most studies addressing prevalence of IBS are community surveys, with the majority from Europe, Southeast Asia, and North America. Often, postal questionnaires or telephone interviews invite individuals to self-report symptoms, and these responses are then assessed by investigators according to one set of diagnostic criteria. This method reflects the underlying burden of symptoms consistent with a diagnosis of IBS. Other studies ask participants if they have ever received a diagnosis of IBS, capturing those who have sought medical advice for their symptoms. The prevalence of IBS within the community is between $10 \%$ and $25 \% .^{20,43,44,57,58,62-65}$ Meta-analysis shows a pooled estimate of international IBS prevalence of $11.2 \%$ (95\% confidence interval [CI] 9.8-12.8), ${ }^{38}$ with variation by geographic region; the lowest occurring in South Asia (7.0\%) and the highest in South America (21.0\%). ${ }^{38}$

Considerable heterogeneity exists between studies. ${ }^{38}$ Some of this is explained through the differences in study methodology and sampling, as described above, and the use of different diagnostic criteria to define IBS, rather than a biological marker, may also account for some of the variation. The Manning criteria account for the highest reported prevalence, ${ }^{13,47}$ whilst the Rome iterations are associated with lower estimates of prevalence that are similar across the iterations..$^{13}$ Meta-analysis has shown that prevalence does not vary significantly according to the calendar year in which studies are conducted. ${ }^{38}$

It is plausible that the underlying prevalence of symptoms in communities internationally is the same, around $11 \%$, and the variations reflect differences in access to health care ${ }^{66,67}$ and acceptability of a diagnosis, both to the physician making the diagnosis and to the patient in receiving and believing it. 5,68 Significant stigma is associated with receiving a diagnosis of a functional disorder as well as seeking health care for IBS

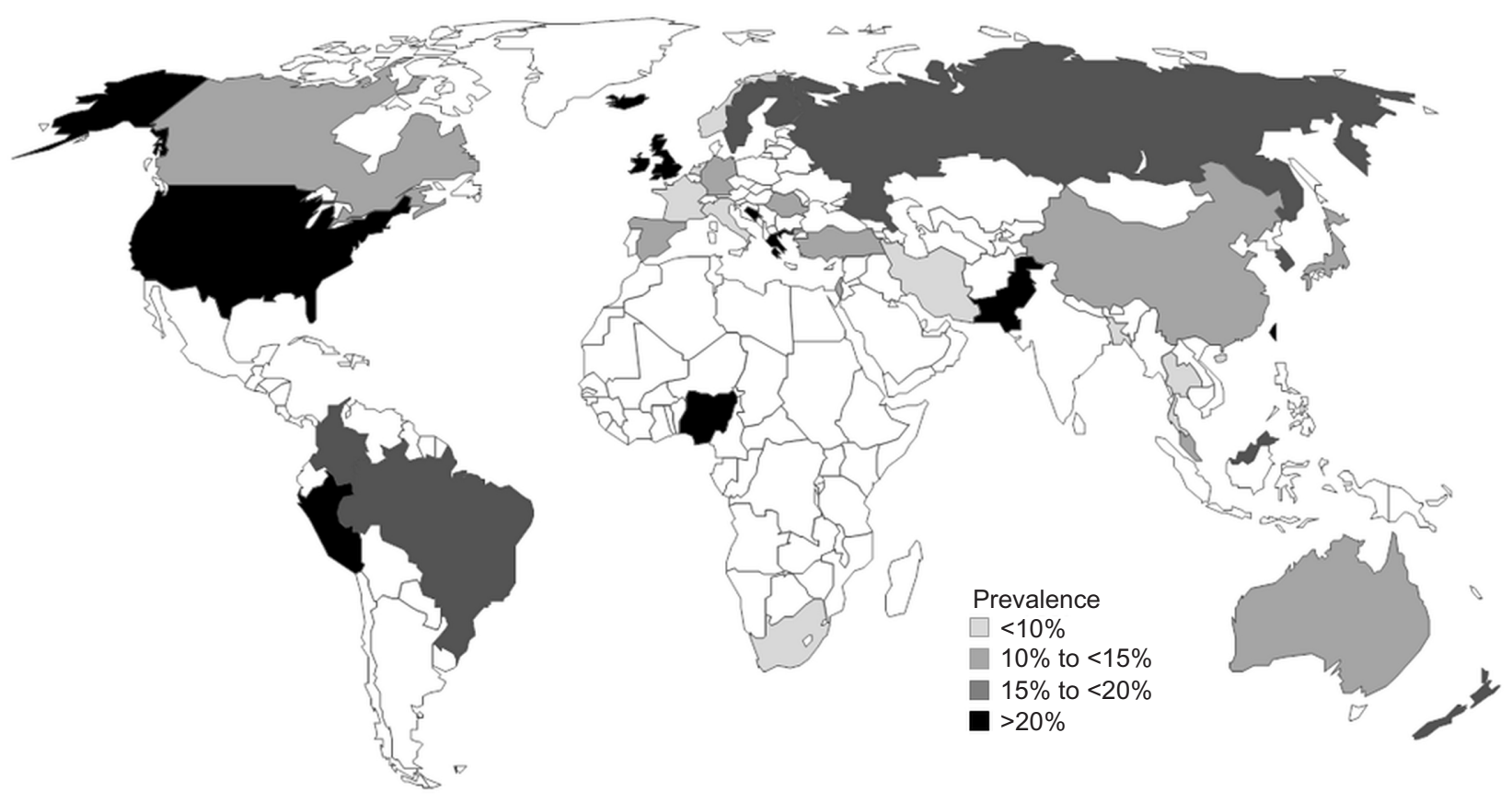

Figure I Worldwide prevalence of irritable bowel syndrome, as reported by country. 
Table 2 Prevalence of irritable bowel syndrome reported internationally, the highest and lowest estimated rates for each country

\begin{tabular}{|c|c|c|c|c|}
\hline Country & $\begin{array}{l}\text { Lowest } \\
\text { estimated } \\
\text { prevalence }\end{array}$ & $95 \% \mathrm{Cl}$ & $\begin{array}{l}\text { Highest } \\
\text { estimated } \\
\text { prevalence }\end{array}$ & $95 \% \mathrm{Cl}$ \\
\hline France & $1.1^{23}$ & NR & $4.7^{24}$ & $4.36-5.04$ \\
\hline Thailand & - & - & $5.7^{25}$ & NR \\
\hline Netherlands & - & - & $5.8^{26}$ & $4.0-9.0$ \\
\hline Hong Kong & $3.7^{27}$ & $2.0-5.2$ & $6.6^{28}$ & NR \\
\hline Italy & - & - & $7.2^{29}$ & $6.0-9.0$ \\
\hline Iran & - & - & $7.1^{30}$ & $6.0-13.0$ \\
\hline South Africa & - & - & $8.1^{31}$ & NR \\
\hline Norway & - & - & $8.4^{32}$ & $7.9-9.4$ \\
\hline Bangladesh & - & - & $8.5^{33}$ & $7.0-10.0$ \\
\hline Turkey & $6.3^{34}$ & $N R$ & $10.2^{35}$ & $6.0-16.0$ \\
\hline Singapore & $2.3^{36}$ & $0.8-3.9$ & $11.0^{37}$ & $9.7-12.3$ \\
\hline Israel & $2.9^{38}$ & $N R$ & $11.4^{38}$ & NR \\
\hline People's & $0.8^{38}$ & NR & $11.5^{39}$ & NR \\
\hline \multicolumn{5}{|l|}{ Republic of } \\
\hline \multicolumn{5}{|l|}{ China } \\
\hline Germany & - & - & $12.5^{40}$ & $10.7-14.5$ \\
\hline Australia & $4.4^{41}$ & $3.6-5.1$ & $13.0^{42}$ & $11.0-16.0$ \\
\hline Pakistan & - & - & $13.3^{43}$ & $4.0-62.0$ \\
\hline Canada & - & - & $13.5^{44}$ & $10.2-14.0$ \\
\hline Japan & $6.1^{45}$ & $5.0-7.0$ & $14.0^{46}$ & $\mathrm{NR}$ \\
\hline Spain & $3.3^{47}$ & $2.1-4.9$ & $14.1^{47}$ & $10.0-18$ \\
\hline Romania & - & - & $14.4^{38}$ & $11.9-19.0$ \\
\hline Sweden & $12.5^{20}$ & $9.0-18.0$ & $15.0^{48}$ & $\mathrm{NR}$ \\
\hline South Korea & $6.6^{49}$ & $2.0-11.0$ & $15.5^{50}$ & $12.0-19.0$ \\
\hline Malaysia & - & - & $15.6^{51}$ & $13.0-18.0$ \\
\hline Finland & $5.1^{52}$ & $4.4-5.8$ & $16.4^{52}$ & $15.0-17.2$ \\
\hline Brazil & - & - & $17.0^{53}$ & $12.0-23.0$ \\
\hline New Zealand & $3.3^{54}$ & $2.1-4.5$ & $18.8^{54}$ & $|6.3-2| .3$ \\
\hline Russia & - & - & $19.0^{38}$ & $17.0-22.0$ \\
\hline Columbia & - & - & $19.9^{38}$ & $16.7-23.3$ \\
\hline USA & $3.0^{55}$ & NR & $20.4^{13}$ & $16.7-24.2$ \\
\hline Taiwan & $17.5^{56}$ & NR & $22.1^{56}$ & NR \\
\hline UK & $6.1^{57}$ & NR & $21.6^{58}$ & NR \\
\hline Greece & - & - & $21.4^{59}$ & NR \\
\hline Peru & $15.0^{38}$ & NR & $24.0^{38}$ & $21.0-28.0$ \\
\hline Croatia & - & - & $28.2^{38}$ & $24.0-32.0$ \\
\hline Iceland & $17.2^{60}$ & $14.4-19.9$ & $30.9^{60}$ & $28.0-33.0$ \\
\hline Nigeria & - & - & $31.6^{61}$ & $27.0-36.0$ \\
\hline
\end{tabular}

Abbreviations: $\mathrm{Cl}$, confidence interval; NR, not reported.

symptoms specifically ${ }^{69,70}$ It is therefore likely that areas where greater stigma is perceived will report lower prevalence, as will populations where symptoms are more often identified as variations of normal. Those communities in which there is higher perceived stress or lower perceived quality of life, greater potential gain from receiving a diagnosis, or fewer barriers to accessing health care will report higher prevalence. ${ }^{71-74}$

\section{Prevalence in primary care}

Many patients do not seek medical attention for symptoms indicative of IBS. ${ }^{18}$ Estimates of the proportion who do attend primary care for their symptoms are between $10 \%{ }^{63}$ and $70 \%{ }^{75}$ In the UK, estimates of the proportion who consult vary from $30 \%{ }^{58}$ to $50 \% .^{57,62,63}$ Reported consultation rates of people with symptoms also vary in studies from Germany, between $10 \%{ }^{63}$ and $50 \%{ }^{40}$ Asking individuals to recall if they have consulted a primary care physician about their symptoms shows that the proportion of patients who report they have attended primary care varies considerably by country across Europe. The highest proportion is in Italy, with 50\% consulting; $30 \%$ consult in the Netherlands, $20 \%$ in Belgium, and $10 \%$ in Switzerland, France, and Spain. ${ }^{63}$ These differences may again reflect differences in diagnostic criteria employed, perceived acceptability of symptoms, and ease of access to primary care, which varies across different health care systems. These studies are also limited by relying on individuals' recall of their behavior. Studies from the USA report more consistently that $30 \%$ of people with symptoms will consult ${ }^{16,65}$ and, of these patients, $80 \%$ have IBS-D. ${ }^{16}$

There are no significant differences in gastrointestinal symptoms between those who consult and those who do not, but those who consult do report higher pain scores, greater levels of anxiety, and greater reduction in quality of life. ${ }^{76,77}$

\section{Who gets IBS? Sex}

In most populations, women report more IBS symptoms than men, irrespective of the diagnostic criteria employed ${ }^{68}$ Rates in women are approximately 1.5 - to 3 -fold higher than those seen in men. ${ }^{12,78,79}$ Internationally, the overall prevalence of IBS in women is $67 \%$ higher than in men (odds ratio 1.67 [95\% CI 1.53-1.82]). This relative difference reflects an absolute difference in prevalence of just over $5 \%$ between the sexes, with a prevalence in women of $14.0 \%$ (95\% CI 11.0-16.0) compared with 8.9\% in men (95\% CI 7.3-10.5). ${ }^{80}$ In South Asia, South America, and Africa, rates of IBS in men are much closer to those of women, and in some cases higher. Consequently, if prevalence is stratified according to geographic region, no significant sex difference can be seen in these areas. ${ }^{80}$ It is possible that this reflects the sex differences in access to health care and symptom normalization in these regions. ${ }^{81,82}$ Equal proportions of men and women with symptoms seek primary care advice. ${ }^{83,84}$

It is likely that the differences in reported sex-specific prevalence occur for reasons similar to those discussed for overall prevalence. It is also probable that the rates reflect differences in illness behavior that motivates consulting and referral patterns rather than the underlying condition. It could 
be argued that the high rate of IBS symptoms in people within the community who do not access health care is a measure of unmet need ${ }^{68}$ However, it could also be considered that symptoms affecting such a high proportion of the population are a variation of normal function.

\section{Age}

IBS occurs in all age groups, including children ${ }^{85}$ and the elderly, with no difference seen in the frequency of subtypes by age. ${ }^{86}$ However, $50 \%$ of patients with IBS report having first had symptoms before the age of 35 years, ${ }^{87}$ and prevalence is $25 \%$ lower in those aged over 50 years than in those who are younger. ${ }^{38}$ This would suggest that symptoms remit over time, and is contrary to the belief that IBS is a chronic lifelong condition, because, if this were the case, then prevalence should remain constant or increase with age. Patients aged over 50 years also report milder pain, but their overall quality of life is worse. ${ }^{86}$ Those aged over 65 years are also likely to have had their symptoms for longer than 1 year before they consult, whilst those under 65 years report significantly shorter duration of symptoms. ${ }^{42}$

\section{Socioeconomic status}

One study suggested that IBS was associated with lower socioeconomic status, ${ }^{65}$ a finding supported by the theory that lower income is associated with poorer health care outcomes, lower overall quality of life, and increased life stressors. ${ }^{88}$ However, others suggest that the opposite is true and that being in a higher socioeconomic group during childhood is associated with higher prevalence of IBS..$^{89,90}$ Similarly, areas in which there is a lower proportion of people employed in manual labor have higher rates of IBS. It is suggested that this is due to the higher level of stress perceived by people working in professional and managerial roles. ${ }^{91}$ This supports the argument that IBS is a disease of industrialization and urbanization, and that the higher rates now being reported in Asia, South America, and Africa are due to increased affluence in these regions. ${ }^{92}$ This may be because those with higher income have greater access to health care and tendency to seek help and hence receive a diagnosis. ${ }^{93}$ It could also reflect differing dietary choices ${ }^{94}$ or greater internalization of stress in higher earning groups. ${ }^{95}$

\section{Family studies}

The relative risk of IBS is twice as high in individuals with a biological relative with IBS. ${ }^{96}$ In twin studies, having a mother or father with IBS is an independent risk factor for an individual having IBS and a stronger predictor than having a twin with IBS. ${ }^{97}$ Concordance in monozygotic twins (the proportion of twin pairs who both have IBS) is less than $20 \%,{ }^{97,98}$ and the association seen in familial clustering is significantly reduced when somatization is adjusted for. ${ }^{99}$ These findings suggest heredity may be more closely linked to learned behavior than to genetic factors. ${ }^{100}$

\section{What is the natural history? Misdiagnosis}

At the time of diagnosis of IBS, rates of organic lesions found on colonoscopy in patients with no red flag symptoms are no higher than seen in healthy controls, ranging from around $10 \%{ }^{101,102}$ to around $40 \%$. ${ }^{103,104}$ Even most patients with alarm symptoms have no organic pathology. ${ }^{105}$

In contrast to the endoscopy findings at diagnosis, in the period following diagnosis the rate of inflammatory bowel disease (IBD) is $9^{106}$ to $16^{21}$ times higher than the general population. The average time between diagnosis of IBS and IBD is $2-3$ years, ${ }^{106,21}$ suggesting that, in some, IBS symptoms are possibly early signs of IBD before lesions are visible. Colorectal cancer incidence is around $1 \%{ }^{21}$ in the first year following diagnosis of IBS, higher than in the general population. After 1 year, the rate returns to the population level.

\section{Symptom patterns}

Symptoms experienced by patients with IBS fluctuate over time. Over short periods of time, as some patients experience resolution of symptoms, others develop new ones, meaning the prevalence of symptomatic IBS remains stable over 1-2 years follow-up. ${ }^{20,83,107}$ In the first 3 months following diagnosis, patients experience four distinct episodes of symptoms per month on average. The longest of these episodes lasts around 5 days, and most patients experience symptoms on more than half of the days. ${ }^{55}$ However, 1 year after initial diagnosis $30 \%-45 \%$ of patients will have prolonged periods that are symptom free, potentially in remission. ${ }^{20,108}$ After 10 years, $50 \%-70 \%$ of patients report persistent symptoms. ${ }^{20,109}$

In patients who do report IBS symptom resolution, 45\% will subsequently experience other functional gastrointestinal symptoms..$^{20,110} \mathrm{Up}$ to two-thirds of IBS patients experience functional dyspepsia, the prevalence of which in patients with IBS is up to seven times higher than in controls. ${ }^{111-113}$

If all gastrointestinal symptoms resolve, then many develop symptoms of other functional diseases. ${ }^{20,114}$ Those with lower quality of life and higher levels of anxiety are more likely to suffer with other functional comorbid conditions. ${ }^{111,115}$ Together with family studies proposing 
consultation behavior is learnt and highly associated with somatization, ${ }^{97,99,116}$ this suggests that IBS is one expression of an underlying tendency toward functional disease.

\section{Co-existing functional conditions}

Fibromyalgia, chronic fatigue syndrome, chronic back pain, chronic pelvic pain, chronic headache, and temporomandibular joint dysfunction exist in approximately half of all patients with IBS, and occur almost twice as often as in the general population. ${ }^{78,111,118}$ These conditions, defined by their symptoms, have considerable overlap and their etiologies are poorly understood. ${ }^{119,120}$ Some people feel these conditions should be considered together under the single umbrella term of 'functional somatic syndromes'. ${ }^{121}$ Whilst these conditions do share some predisposing risk factors, the triggers for developing each condition vary. ${ }^{120}$ Multivariate analysis supports the idea that somatic comorbidities seen in IBS are distinct disorders and not manifestations of one somatization disorder. ${ }^{118}$ Even so, patients who have IBS and other somatic comorbidities report more severe symptoms than those patients with IBS alone. ${ }^{11,115,122}$ In addition, over one-half of all patients with IBS report depression or anxiety, ${ }^{86,115,120,123}$ and these patients experience more severe somatic symptoms. ${ }^{124}$

\section{Surgery}

Symptoms of IBS have considerable overlap with organic gastrointestinal and pelvic pathologies. Consequently, patients with IBS are at risk of undergoing unnecessary surgical procedures due to misdiagnosis..$^{93,125}$ The likelihood of having cholecystectomy is between two ${ }^{126}$ and three ${ }^{127}$ times as high in IBS as in the general public, and patients with IBS are almost twice as likely to have appendectomies ${ }^{63,127}$ or hysterectomies. ${ }^{127}$

\section{Mortality}

IBS is a functional disease that significantly reduces patients' quality of life, is associated with depression and suicidal ideation, and patients have an increased frequency of invasive procedures and surgery. ${ }^{118,127}$ Despite this, community-based studies have shown that IBS is not associated with any increased mortality. ${ }^{128,129} \mathrm{~A}$ large study in the USA of over 4,000 patients, followed for a total of 30,000 patient-years, and with 1,101 deaths, observed no increased mortality compared with the general population (hazard rate 1.06 [95\% CI 0.86-1.32]). ${ }^{128}$ A recent much smaller study from the People's Republic of China followed 263 patients over 5 years and found the same. They did notice that the incidence of colorectal cancer was increased, especially in elderly patients with IBS-C, where it was 7.5 times that of the general population. This possibly reflects misdiagnosis or ascertainment bias. ${ }^{129}$

\section{Summary}

IBS is a significant health care burden, irrespective of setting or geography, affecting around $11 \%$ of the population globally.

Accurate case definition remains difficult in IBS due to the high frequency of symptoms within the community, variations in diagnostic criteria and the stringency with which they are implemented, lack of specific histopathological changes, and lack of a definitive point of onset. This makes epidemiological studies challenging, with rates dependent on the methods chosen to define and measure IBS, so the literature should be considered within this context.

Evidence of lower prevalence of IBS in older age groups suggests that symptoms resolve over time, but this is contradicted by natural history studies, which imply chronicity of symptoms. A significant amount of evidence also suggests that patients with IBS are more likely to also have other functional conditions. Evidence suggests that 'symptom shifting' occurs in a proportion of patients, where resolution of functional bowel symptoms sees development of functional symptoms in another system.

Older studies suggest a high secondary care burden of IBS, with it accounting for up to $50 \%$ of gastrointestinal outpatient clinic time. However, these are highly biased estimates, often reliant on questioning physicians about their perceived workload. More recent studies would suggest IBS accounts for closer to $20 \%$ of gastroenterology outpatient work, possibly in part reflecting changes in primary care referral guidelines. Even so, this remains a significant proportion and highlights the importance of continuing to improve diagnosis and management of these individuals, to optimize their health care utilization and fully assess the impact and benefit of different management approaches.

\section{Disclosure}

$\mathrm{CC}$ is funded through a Population Health Scientist Fellowship from the Medical Research Council. JW is funded by a Nottingham University Hospitals National Health Service Trust/University of Nottingham Senior Clinical Research Fellowship. The authors report no conflicts of interest in this work.

\section{References}

1. Chaudhary NA, Truelove SC. The irritable colon syndrome. A study of the clinical features, predisposing causes, and prognosis in 130 cases. QJ Med. 1962;31:307-322. 
2. Kruse FH. Functional disorders of the colon: the spastic colon, the irritable colon, and mucous colitis. Cal West Med. 1933;39(2):97-103.

3. No authors listed. Irritable bowel syndrome. Br Med J. 1972;1(5794): 197-198.

4. Longstreth GF, Thompson WG, Chey WD, Houghton LA, Mearin F, Spiller RC. Functional bowel disorders. Gastroenterology. 2006;130(5): 1480-1491.

5. Spiegel BM, Farid M, Esrailian E, Talley J, Chang L. Is irritable bowel syndrome a diagnosis of exclusion? A survey of primary care providers, gastroenterologists, and IBS experts. Am J Gastroenterol. 2010;105(4): 848-858.

6. Mearin F, Lacy BE. Diagnostic criteria in IBS: useful or not? Neurogastroenterol Motil. 2012;24(9):791-801.

7. Engsbro AL, Begtrup LM, Kjeldsen J, et al. Patients suspected of irritable bowel syndrome: cross-sectional study exploring the sensitivity of Rome III criteria in primary care. Am J Gastroenterol. 2013;108(6): 972-980.

8. Quigley EM. The 'con' case. The Rome process and functional gastrointestinal disorders: the barbarians are at the gate! Neurogastroenterol Motil. 2007;19(10):793-797.

9. Quigley EMM, Fried M, Gwee K-A, et al. Irritable Bowel Syndrome: A Global Perspective. Milwaukee (WI): World Gastroenterology Organisation; 2009:1-20.

10. Whitehead WE, Drossman DA. Validation of symptom-based diagnostic criteria for irritable bowel syndrome: a critical review. $A m \mathrm{~J}$ Gastroenterol. 2010;105(4):814-820; quiz 813, 821.

11. Whitehead WE, Palsson OS, Feld AD, et al. Utility of red flag symptom exclusions in the diagnosis of irritable bowel syndrome. Aliment Pharmacol Ther. 2006;24(1):137-146.

12. Manning AP, Thompson WG, Heaton KW, Morris AF. Towards positive diagnosis of the irritable bowel. $\mathrm{Br}$ Med J. 1978;2(6138): 653-654.

13. Saito YA, Locke GR, Talley NJ, Zinsmeister AR, Fett SL, Melton LJ 3rd. A comparison of the Rome and Manning criteria for case identification in epidemiological investigations of irritable bowel syndrome. Am J Gastroenterol. 2000;95(10):2816-2824.

14. Thompson WG, Longstreth GF, Drossman DA, Heaton KW, Irvine EJ, Müller-Lissner SA. Functional bowel disorders and functional abdominal pain. Gut. 1999;45 Suppl 2:II43-II47.

15. Ford AC, Talley NJ. Irritable bowel syndrome. BMJ. 2012;345 e5836.

16. Hungin AP, Chang L, Locke GR, Dennis EH, Barghout V. Irritable bowel syndrome in the United States: prevalence, symptom patterns and impact. Aliment Pharmacol Ther. 2005;21(11):1365-1375.

17. Thompson WG, Heaton KW, Smyth GT, Smyth C. Irritable bowel syndrome in general practice: prevalence, characteristics, and referral. Gut. 2000;46(1):78-82.

18. Chang SY, Jones MP. Consulters and nonconsulters in irritable bowel syndrome: what makes an IBS patient? Pract Gastroenterol. 2003;6:15-26.

19. Talley NJ, Weaver A, Zinsmeister AR, Melton LJ 3rd. Onset and disappearence of gastrointestinal symptoms and functional gastrointestinal disorders. Am J Epidemiol. 1992;136(2):165-177.

20. Agreus L, Svärdsudd K, Nyrén O, Tibblin G. Irritable bowel syndrome and dyspepsia in the general population: overlap and lack of stability over time. Gastroenterology. 1995;109(3):671-680.

21. García Rodríguez LA, Ruigómez A, Wallander MA, Johansson S, Olbe L. Detection of colorectal tumor and inflammatory bowel disease during follow-up of patients with initial diagnosis of irritable bowel syndrome. Scand J Gastroenterol. 2000;35(3):306-311.

22. Locke GR 3rd, Yawn BP, Wollan PC, Melton LJ 3rd, Lydick E, Talley NJ. Incidence of a clinical diagnosis of the irritable bowel syndrome in a United States population. Aliment Pharmacol Ther. 2004; 19(9):1025-1031.

23. Bommelaer G, Poynard T, Le Pen C, et al. Prevalence of irritable bowel syndrome (IBS) and variability of diagnostic criteria. Gastroenterol Clin Biol. 2004;28(6-7 Pt 1):554-561.
24. Dapoigny M, Bellanger J, Bonaz B, et al. Irritable bowel syndrome in France: a common, debilitating and costly disorder. Eur J Gastroenterol Hepatol. 2004;16(10):995-1001.

25. Danivat D, Tankeyoon M, Sriratanaban A. Prevalence of irritable bowel syndrome in a non-Western population. Br Med J (Clin Res Ed). 1988;296(6638):1710.

26. Boekema P, van Dam van Isselt EF, Bots ML, Smout AJ. Functional bowel symptoms in a general Dutch population and associations with common stimulants. Neth J Med. 2001;59(1):23-30.

27. Lau EM, Chan FK, Ziea ET, Chan CS, Wu JC, Sung JJ. Epidemiology of irritable bowel syndrome in Chinese. Dig Dis Sci. 2002;47(11):2621-2624.

28. Kwan AC, Hu WH, Chan YK, Yeung YW, Lai TS, Yuen H. Prevalence of irritable bowel syndrome in Hong Kong. J Gastroenterol Hepatol. 2002;17(11):1180-1186.

29. Usai P, Manca R, Lai MA, et al. Prevalence of irritable bowel syndrome in Italian rural and urban areas. Eur J Intern Med. 2010;21(4): 324-326.

30. Amra B, Hoseini-Asl MK, Rahmani AR, Golshan M, Mohamad-Zadeh Z. Correlation between asthma and irritable bowel syndrome in a general population in Iran in 2003. Respir Med. 2006;100(1):110-114.

31. Segal I, Walker AR. The irritable bowel syndrome in the black community. S Afr Med J. 1984;65(3):72-73.

32. Vandvik PO, Lydersen S, Farup PG. Prevalence, comorbidity and impact of irritable bowel syndrome in Norway. Scand J Gastroenterol. 2006;41(6):650-656.

33. Perveen I, Hasan M, Masud MA, Bhuiyan MM, Rahman MM. Irritable bowel syndrome in a Bangladeshi urban community: prevalence and health care seeking pattern. Saudi J Gastroenterol. 2009;15(4): 239-243.

34. Celebi S, Acik Y, Deveci SE, et al. Epidemiological features of irritable bowel syndrome in a Turkish urban society. J Gastroenterol Hepatol. 2004;19(7):738-743.

35. Yilmaz S, Dursun M, Ertem M, Canoruc F, Turhanoğlu A. The epidemiological aspects of irritable bowel syndrome in Southeastern Anatolia: a stratified randomised community-based study. Int J Clin Pract. 2005;59(3):361-369.

36. Ho KY, Kang JY, Seow A. Prevalence of gastrointestinal symptoms in a multiracial Asian population, with particular reference to reflux-type symptoms. Am J Gastroenterol. 1998;93(10):1816-1822.

37. Gwee KA, Wee S, Wong ML, Png DJ. The prevalence, symptom characteristics, and impact of irritable bowel syndrome in an asian urban community. Am J Gastroenterol. 2004;99(5):924-931.

38. Lovell RM, Ford AC. Global prevalence of and risk factors for irritable bowel syndrome: a meta-analysis. Clin Gastroenterol Hepatol. 2012;10(7):712-721. e4

39. Xiong LS, Chen MH, Chen HX, Xu AG, Wang WA, Hu PJ. A population-based epidemiologic study of irritable bowel syndrome in South China: stratified randomized study by cluster sampling. Aliment Pharmacol Ther. 2004;19(11):1217-1224.

40. Icks A, Haastert B, Enck P, Rathmann W, Giani G. Prevalence of functional bowel disorders and related health care seeking: a populationbased study. Z Gastroenterol. 2002;40(3):177-183.

41. Boyce PM, Talley NJ, Burke C, Koloski NA. Epidemiology of the functional gastrointestinal disorders diagnosed according to Rome II criteria: an Australian population-based study. Intern Med J. 2006;36(1): 28-36.

42. Talley NJ, Boyce PM, Jones M. Predictors of health care seeking for irritable bowel syndrome: a population based study. Gut. 1997;41(3): 394-398.

43. Husain N, Chaudhry IB, Jafri F, Niaz SK, Tomenson B, Creed F. A population-based study of irritable bowel syndrome in a non-Western population. Neurogastroenterol Motil. 2008;20(9):1022-1029.

44. Thompson WG, Irvine EJ, Pare P, Ferrazzi S, Rance L. Functional gastrointestinal disorders in Canada: first population-based survey using Rome II criteria with suggestions for improving the questionnaire. Dig Dis Sci. 2002;47(1):225-235. 
45. Kumano H, Kaiya H, Yoshiuchi K, Yamanaka G, Sasaki T, Kuboki T. Comorbidity of irritable bowel syndrome, panic disorder, and agoraphobia in a Japanese representative sample. Am J Gastroenterol. 2004; 99(2):370-376.

46. Hongo M. Epidemiology of FGID symptoms in Japanese general population with reference to life style. J Gastroenterol Hepatol. 2011; 26 Suppl 3:19-22.

47. Mearin F, Badía X, Balboa A, et al. Irritable bowel syndrome prevalence varies enormously depending on the employed diagnostic criteria: comparison of Rome II versus previous criteria in general population. Scand J Gastroenterol. 2001;36(11):1155-1161.

48. Walter SA, Kjellström L, Nyhlin H, Talley NJ, Agréus L. Assessment of normal bowel habits in the general adult population: the Popcol study. Scand J Gastroenterol. 2010;45(5):556-566.

49. Han SH, Lee OY, Bae SC, et al. Prevalence of irritable bowel syndrome in Korea: population-based survey using the Rome II criteria. J Gastroenterol Hepatol. 2006;21(11):1687-1692.

50. Choo KY, Choi MG, Choi H, et al. The prevalences of gastrointestinal symptoms in a rural community in Korea. Korean J Gastrointest Motil. 2000;6(1):31-43.

51. Rajendra S, Alahuddin S. Prevalence of irritable bowel syndrome in a multi-ethnic Asian population. Aliment Pharmacol Ther. 2004;19(6): 704-706.

52. Hillilä MT, Färkkilä MA. Prevalence of irritable bowel syndrome according to different diagnostic criteria in a non-selected adult population. Aliment Pharmacol Ther. 2004;20(3):339-345.

53. Soares RL, dos Santos JM, Rocha VR. Prevalence of irritable bowel syndrome in a Brazilian Amazon community. Neurogastroenterol Motil. 2005; 17(6):883

54. Barbezat G, Poulton R, Milne B, Howell S, Fawcett JP, Talley N. Prevalence and correlates of irritable bowel syndrome symptoms in a New Zealand birth cohort. N Z Med J. 2002;115(1164):U220.

55. Hahn BA, Saunders WB, Maier WC. Differences between individuals with self-reported irritable bowel syndrome (IBS) and IBS-like symptoms. Dig Dis Sci. 1997;42(12):2585-2590.

56. Lu CL, Chen CY, Lang HC, et al. Current patterns of irritable bowel syndrome in Taiwan: the Rome II questionnaire on a Chinese population. Aliment Pharmacol Ther. 2003;18(11-12):1159-1169.

57. Heaton KW, O’Donnell LJ, Braddon FE, Mountford RA, Hughes AO, Cripps PJ. Symptoms of irritable bowel syndrome in a British urban community: consulters and nonconsulters. Gastroenterology. 1992; 102(6):1962-1967.

58. Jones R, Lydeard S. Irritable bowel syndrome in the general population. BMJ. 1992;304(6819):87-90.

59. Papatheodoridis GV, Karamanolis DG. Prevalence and impact of upper and lower sastrointestinal Symptoms in the Greek urban general population. Scand J Gastroenterol. 2005;40(4):412-421.

60. Olafsdottir LB, Gudjonsson H, Jonsdottir HH, Bjornsson E, Thjodleifsson B. Natural history of functional gastrointestinal disorders: comparison of two longitudinal population-based studies. Dig Liver Dis. 2012;44(3):211-217.

61. Okeke EN, Ladep NG, Adah S, Bupwatda PW, Agaba EI, Malu AO. Prevalence of irritable bowel syndrome: a community survey in an African population. Ann Afr Med. 2009;8(3):177-180.

62. Wilson S, Roberts L, Roalfe A, Bridge P, Singh S. Prevalence of irritable bowel syndrome: a community survey. Br J Gen Pract. 2004;54(504): 495-502.

63. Hungin AP, Whorwell PJ, Tack J, Mearin F. The prevalence, patterns and impact of irritable bowel syndrome: an international survey of 40,000 subjects. Aliment Pharmacol Ther. 2003;17(5):643-650.

64. Goodwin L, White PD, Hotopf M, Stansfeld SA, Clark C. Life course study of the etiology of self-reported irritable bowel syndrome in the 1958 British birth cohort. Psychosom Med. 2013;75(2): 202-210.

65. Drossman DA, Li Z, Andruzzi E, et al. US householder survey of functional gastrointestinal disorders. Prevalence, sociodemography, and health impact. Dig Dis Sci. 1993;38(9):1569-1580.
66. Haas J, Phillips K, Sonneborn D, et al. Variation in access to health care for different racial/ethnic groups by the racial/ethnic composition of an individual's contry of residence. Med Care. 2004:42(7):707-714.

67. Grundmann O, Yoon SL. Irritable bowel syndrome: epidemiology, diagnosis and treatment: an update for health-care practitioners. J Gastroenterol Hepatol. 2010;25(4):691-699.

68. Quigley EM, Bytzer P, Jones R, Mearin F. Irritable bowel syndrome: the burden and unmet needs in Europe. Dig Liver Dis. 2006;38(10): 717-723.

69. Dancey CP, Hutton-Young SA, Moye S, Devins GM. Perceived stigma, illness intrusiveness and quality of life in men and women with irritable bowel syndrome. Psychol Health Med. 2002;7(4):381-395.

70. Jones MP, Keefer L, Bratten J, et al. Development and initial validation of a measure of perceived stigma in irritable bowel syndrome. Psychol Health Med. 2009;14(3):367-374.

71. Nettleton S. 'I just want permission to be ill': towards a sociology of medically unexplained symptoms. Soc Sci Med. 2006;62(5):1167-1178.

72. Farmer J, Iversen L, Campbell NC, et al. Rural/urban differences in accounts of patients' initial decisions to consult primary care. Health Place. 2006;12(2):210-221.

73. Cummings KM, Becker MH, Maile MC. Bringing the models together: an empirical approach to combining variables used to explain health actions. J Behav Med. 1980;3(2):123-145.

74. Zola IK. Pathways to the doctor - from person to patient. Soc Sci Med. 1973;7(9):677-689.

75. Koloski NA, Talley NJ, Huskic SS, Boyce PM. Predictors of conventional and alternative health care seeking for irritable bowel syndrome and functional dyspepsia. Aliment Pharmacol Ther. 2003;17(6): 841-851.

76. Creed F. Who needs a doctor for IBS? Gut. 1997;41(3):415-416.

77. Lee V, Guthrie E, Robinson A, et al. Functional bowel disorders in primary care: factors associated with health-related quality of life and doctor consultation. J Psychosom Res. 2008;64(2):129-138.

78. Kennedy TM, Jones RH, Hungin AP, O'flanagan H, Kelly P. Irritable bowel syndrome, gastro-oesophageal reflux, and bronchial hyperresponsiveness in the general population. Gut. 1998;43(6):770-774.

79. Drossman DA, Funch-Jensen P, Janssens J. Identification of subgroups of functional bowel disorders. Gastroenterol Int. 1990;(3):159-172. Available from: http://www.scopus.com/record/display.url?eid=2s2.0-0025601811\&origin $=$ resultslist\&zone $=$ contextBox. Accessed December 17, 2013

80. Lovell RM, Ford AC. Effect of gender on prevalence of irritable bowel syndrome in the community: systematic review and meta-analysis. Am J Gastroenterol. 2012;107(7):991-1000.

81. Merzel C. Gender differences in health care access indicators in an urban, low-income community. Am J Public Health. 2000;90(6):909-916.

82. World Health Organization. Why Gender and Health? Geneva: World Health Organization; 2013. Available from: http://www.who.int/gender/ genderandhealth/en/. Accessed July 18, 2013.

83. Williams RE, Black CL, Kim HY, et al. Determinants of healthcareseeking behaviour among subjects with irritable bowel syndrome. Aliment Pharmacol Ther. 2006;23(11):1667-1675.

84. Lee OY, Mayer EE, Schmulson M, Chang L, Naliboff B. Gender related differences in IBS symptoms. Am J Gastroenterol. 2001;96(7): 2184-2196.

85. Rasquin A, Di Lorenzo C, Forbes D, et al. Childhood functional gastrointestinal disorders: child/adolescent. Gastroenterology. 2006;130(5):1527-1537.

86. Tang YR, Yang WW, Liang ML, Xu XY, Wang MF, Lin L. Age-related symptom and life quality changes in women with irritable bowel syndrome. World J Gastroenterol. 2012;18(48):7175-7183.

87. Maxwell PR, Mendall MA, Kumar D. Irritable bowel syndrome. Lancet. 1997;350(9092):1691-1695.

88. Marmot M, Allen J, Bell R, Bloomer E, Goldblatt P; Consortium for the European Review of Social Determinants of Health and the Health Divide. WHO European review of social determinants of health and the health divide. Lancet. 2012;380(9846):1011-1029.

89. Mendall MA, Kumar D. Antibiotic use, childhood affluence and irritable bowel syndrome (IBS). Eur J Gastroenterol Hepatol. 1998;10(1): $59-62$. 
90. Howell S, Talley NJ, Quine S, Poulton R. The irritable bowel syndrome has origins in the childhood socioeconomic environment. Am J Gastroenterol. 2004;99(8):1572-1578.

91. Grodzinsky E, Hallert C, Faresjö T, Bergfors E, Faresjö AO. Could gastrointestinal disorders differ in two close but divergent social environments? Int J Health Geogr. 2012;11:5.

92. Gwee KA. Irritable bowel syndrome in developing countries: a disorder of civilization or colonization? Neurogastroenterol Motil. 2005;17(3):317-324.

93. Cremonini F, Talley NJ. Irritable bowel syndrome: epidemiology, natural history, health care seeking and emerging risk factors. Gastroenterol Clin North Am. 2005;34(2):189-204.

94. Hulshof KF, Brussaard JH, Kruizinga AG, Telman J, Löwik MR. Socioeconomic status, dietary intake and $10 \mathrm{y}$ trends: the Dutch National Food Consumption Survey. Eur J Clin Nutr. 2003;57(1):128-137.

95. Talley NJ, Phillips SF, Bruce B, Twomey CK, Zinsmeister AR, Melton LJ. Relation among personality and symptoms in nonulcer dyspepsia and the irritable bowel syndrome. Gastroenterology. 1990;99(2):327-333.

96. Locke GR 3rd, Zinsmeister AR, Talley NJ, Fett SL, Melton LJ 3rd. Familial association in adults with functional gastrointestinal disorders. Mayo Clin Proc. 2000;75(9):907-912.

97. Levy RL, Jones KR, Whitehead WE, Feld SI, Talley NJ, Corey LA. Irritable bowel syndrome in twins: heredity and social learning both contribute to etiology. Gastroenterology. 2001;121(4):799-804.

98. Morris-Yates A, Talley NJ, Boyce PM, Nandurkar S, Andrews G. Evidence of a genetic contribution to functional bowel disorder. Am J Gastroenterol. 1998;93(8):1311-1317.

99. Mohammed I, Cherkas LF, Riley SA, Spector TD, Trudgill NJ. Genetic influences in irritable bowel syndrome: a twin study. Am J Gastroenterol. 2005;100(6):1340-1344.

100. Hopper JL, Bishop DT, Easton DF. Population-based family studies in genetic epidemiology. Lancet. 2005;366(9494):1397-1406.

101. Ishihara S, Yashima K, Kushiyama Y, et al. Prevalence of organic colonic lesions in patients meeting Rome III criteria for diagnosis of IBS: a prospective multi-center study utilizing colonoscopy. J Gastroenterol. 2012;47(10):1084-1090.

102. Chey WD, Nojkov B, Rubenstein JH, Dobhan RR, Greenson JK, Cash BD. The yield of colonoscopy in patients with non-constipated irritable bowel syndrome: results from a prospective, controlled US trial. Am J Gastroenterol. 2010;105(4):859-865.

103. Akhtar AJ, Shaheen MA, Zha J. Organic colonic lesions in patients with irritable bowel syndrome (IBS). Med Sci Monit. 2006;12(9): CR363-CR367.

104. Gu HX, Zhang YL, Zhi FC, Jiang B, Huang Y. Organic colonic lesions in 3,332 patients with suspected irritable bowel syndrome and lacking warning signs, a retrospective case-control study. Int J Colorectal Dis. 2011;26(7):935-940.

105. Black TP, Manolakis CS, Di Palma JA. "Red flag" evaluation yield in irritable bowel syndrome. J Gastrointestin Liver Dis. 2012;21(2): 153-156.

106. Porter CK, Cash BD, Pimentel M, Akinseye A, Riddle MS. Risk of inflammatory bowel disease following a diagnosis of irritable bowel syndrome. BMC Gastroenterol. 2012;12:55.

107. Mearin F, Baró E, Roset M, Badía X, Zárate N, Pérez I. Clinical patterns over time in irritable bowel syndrome: symptom instability and severity variability. Am J Gastroenterol. 2004;99(1):113-121.

108. Talley NJ, Zinsmeister AR, Van Dyke C, Melton LJ 3rd. Epidemiology of colonic symptoms and the irritable bowel syndrome. Gastroenterology. 1991;101(4):927-934.

109. Ford AC, Forman D, Bailey AG, Axon AT, Moayyedi P. Irritable bowel syndrome: a 10-yr natural history of symptoms and factors that influence consultation behavior. Am J Gastroenterol. 2008;103(5):12291239; quiz 1240 .
110. Agréus L, Svärdsudd K, Talley NJ, Jones MP, Tibblin G. Natural history of gastroesophageal reflux disease and functional abdominal disorders: a population based study. Am J Gastroenterol. 2001;96(10): 2905-2914.

111. Hillilä MT, Siivola MT, Färkkilä MA. Comorbidity and use of healthcare services among irritable bowel syndrome sufferers. Scand J Gastroenterol. 2007;42(7):799-806.

112. Talley NJ, Dennis EH, Schettler-Duncan VA, Lacy BE, Olden KW, Crowell MD. Overlapping upper and lower gastrointestinal symptoms in irritable bowel syndrome patients with constipation or diarrhea. Am J Gastroenterol. 2003;98(11):2454-2459.

113. Stanghellini V, Tosetti C, Barbara G, et al. Dyspeptic symptoms and gastric emptying in the irritable bowel syndrome. Am J Gastroenterol. 2002;97(11):2738-2743.

114. Vandvik PO, Wilhelmsen I, Ihlebaek C, Farup PG. Comorbidity of irritable bowel syndrome in general practice: a striking feature with clinical implications. Aliment Pharmacol Ther. 2004;20(10): 1195-1203.

115. Sperber AD, Atzmon Y, Neumann L, et al. Fibromyalgia in the irritable bowel syndrome: studies of prevalence and clinical implications. $\mathrm{Am}$ J Gastroenterol. 1999;94(12):3541-3546.

116. Whitehead WE. Twin studies used to prove that the comorbidity of major depressive disorder with IBS is NOT influenced by heredity. Am J Gastroenterol. 2007;102(10):2230-2231.

117. Markowitz M, Harris W, Ricci J, et al. Comorbid conditions in patients with irritable bowel syndrome: Data from a national IBS awareness registry. Gastroenterology. 2001;120(5 Suppl 1):A231.

118. Whitehead WE, Palsson O, Jones KR. Systematic review of the comorbidity of irritable bowel syndrome with other disorders: what are the causes and implications? Gastroenterology. 2002;122(4): 1140-1156.

119. Aaron LA, Buchwald D. A review of the evidence for overlap among unexplained clinical conditions. Ann Intern Med. 2001;134(9 Pt 2): 868-881.

120. Hamilton WT, Gallagher AM, Thomas JM, White PD. Risk markers for both chronic fatigue and irritable bowel syndromes: a prospective casecontrol study in primary care. Psychol Med. 2009;39(11): 1913-1921.

121. Aggarwal VR, McBeth J, Zakrzewska JM, Lunt M, Macfarlane GJ. The epidemiology of chronic syndromes that are frequently unexplained: do they have common associated factors? Int J Epidemiol. 2006;35(2):468-476.

122. Longstreth GF. Irritable bowel syndrome. Diagnosis in the managed care era. Dig Dis Sci. 1997;42(6):1105-1111.

123. Przekop P, Haviland MG, Zhao Y, Oda K, Morton KR, Fraser GE. Self-reported physical health, mental health, and comorbid diseases among women with irritable bowel syndrome, fibromyalgia, or both compared with healthy control respondents [Erratum appears in J Am Osteopath Assoc. Jan 2013;113(1):15]. J Am Osteopath Assoc. 2012;112(11):726-735.

124. Lackner JM, Ma CX, Keefer L, et al. Type, rather than number, of mental and physical comorbidities increases the severity of symptoms in patients with irritable bowel syndrome. Clin Gastroenterol Hepatol. 2013;11(9):1147-1157.

125. Longstreth GF. Avoiding unnecessary surgery in irritable bowel syndrome. Gut. 2007;56(5):608-610.

126. Kennedy TM, Jones RH. Epidemiology of cholecystectomy and irritable bowel syndrome in a UK population. Br J Surg. 2000;87(12): 1658-1663.

127. Longstreth GF, Yao JF. Irritable bowel syndrome and surgery: a multivariable analysis. Gastroenterology. 2004;126(7):1665-1673.

128. Chang JY, Locke GR 3rd, McNally MA, et al. Impact of functional gastrointestinal disorders on survival in the community. $\mathrm{Am} \mathrm{J}$ Gastroenterol. 2010;105(4):822-832.

129. Tang YR, Wang P, Yin R, Ge JX, Wang GP, Lin L. Five-year follow-up of 263 cases of functional bowel disorder. World $J$ Gastroenterol. 2013;19(9):1466-1471. 


\section{Publish your work in this journal}

Clinical Epidemiology is an international, peer-reviewed, open access journal focusing on disease and drug epidemiology, identification of risk factors and screening procedures to develop optimal preventative initiatives and programs. Specific topics include: diagnosis, prognosis, treatment, screening, prevention, risk factor modification, systematic

Submit your manuscript here: http://www.dovepress.com/clinical-epidemiology-journal reviews, risk \& safety of medical interventions, epidemiology \& biostatical methods, evaluation of guidelines, translational medicine, health policies \& economic evaluations. The manuscript management system is completely online and includes a very quick and fair peer-review system, which is all easy to use. 